\title{
Science Fiction between Virtual Space Opera's Adventure and the Alienation of Future Cities in Movie Poster Design
}

\author{
Ahmed Obaid Kadhim, Kufa University, College of Education, Department of Art Education, \\ Ahmedo.Kadhim@uokufa.edu.iq
}

\begin{abstract}
One of the characteristics of science fiction literature is the promotion of the idea of adventure in building capabilities and making the impossible possible from the logic of domination and seizure of an approach that calls for the return of the invasion and occupation of technologically advanced beings that establish a pattern of tension in relationships, as digital technology contributes to crystallizing their own ideas and contents through the space surrounding people, their clothes, bodies, and their combat tools. The lasers, animals, mythical shapes and fast-moving vehicles, both land and air, are commensurate with the narratives of the epic space opera, as it deals with tales of a mythical character with bright light reflections to confirm that the image does not convey a real reality, but rather a picture of an idea that stimulates the imagination, and the problem of the current research has been identified with the following: How it responded Science fiction literature for a virtual space opera adventure style in Star Wars movie series poster design? Does the concept of Darwinian evolution have a holistic connotation in future cities in the design of Star Wars posters? The importance of the current research has also been determined through the openness of the creative artistic work to scientific and technical laws and theories with the literary and artistic imagination unlimited, with its weak presence in the Arab and Iraqi world in particular, and the inability to achieve a balance in the concepts of originality, modernity and technological progress, and the ultimate goal is to identify literary conceptual frameworks and artistic science fiction.
\end{abstract}

Keywords: Science Fiction; Virtual Space Opera; Future Cities; and Movie Poster Design. Received: 04.12.2020 Accepted: 08.01.2021 Published: 04.02.2021

\section{METHODOLOGICAL FRAMEWORK FOR RESEARCH}

\section{The Research Problem}

The visual scene and what goes on in the dramatic space presented by cinema at the level of intellectual and aesthetic craftsmanship occupies a large area in global display screens that depend on imagination and innovation, and the creation of complex and dangerous ideas and topics that require very modern techniques in the implementation of visual and audio effects, and here the skills of the recipient move into operating situations Symmetry, closeness, and similarity with actions and characters that reach the point of uniting with the other self or borrowing its role to coexist with what it plays in the role, this creates a state of merging the image of the film with the dream and imagination of the recipient in search of pleasure, and meaning through the overlapping of tenses and open ends, confusion, maze and amazement and raising questions without obtaining answers. Here, ultramodern cinema enjoys its digital presence an important place as the contemporary culture dominant in the global aesthetic discourse. Perhaps the basis of the postmodern cultural project is the principle of aesthetics of contrast and rejection and breaking the expectation and the familiar in a virtual world that transcends the concerns of the recipient and his reality. And because the digital revolution has come into direct contact with our senses and thoughts on a daily and direct basis, here we find the achievements of literature and art including the graphic design of poster art for the Hollywood Film Production Corporation, such as the Star Wars films series, where technology and the experimental aspect represent the most important tools of the era's culture and its radical transformations as a new metaphysical principle, but rather a new pressing power that is not just a formal shift but one of the elements of the contemporary intellectual structure, whose goal is to reproduce reality and controlling it with a hypothetical metaphor outside the geographical space, such as the collage technique and the copying of compensation from the objective place to another more delusional and imaginative in the vastness of space and the depths of the earth. In the beginning, man thought himself alone in this universe, as he imagined that the globe on which he lives is a center The universe revolves around and around the seven planets, and I believe that it is the oldest and most worthy of honor, supremacy and sovereignty, hegemony, technology and technology within virtual worlds capable of formulating them, digital programs he creates, and photographic skills for 
photographic filters he excels in producing all of which are employed in a way that promotes anxiety, suspicion and suspicion in targeting his pictorial memory in determinants of time and place targeting his date and his identity and legacy as the culmination of a human adventure in a sincere and rapid presentation of the idea of Darwinian evolution and the struggle for survival, and the Darwinian proposal claiming that contact with other worlds will generate a struggle for control and control. In its forms and fiercest, and because the existence in the design of the movie poster for the Star Wars series proposes and the balance lives in a sea of conflict, the mythical scenes of the war of virtual worlds take the causes of strength for change and victory by controlling the digital world and ensuring the supremacy and uniqueness of the United States of America, as a systematic policy pursued by the Western strategic mind In dealing with international issues, to reach a new political position or reality, which sees chaos, devastation and divisions in the world as a cultural and ethical source that refuses to create a balanced and just global order, leading to the dismantling of the global order based on the sovereignty of states, all that is mentioned is a presentation and exploration of knowledge as a scientific stage that finds in the reality of the conquest and occupation and systematically a colonial logic for an adventure in the form of science fiction stories depicting other planets and worlds as nations and virtual colonies to project global trends onto the solar system.

\section{Importance and Need of the Research}

1. The openness of the creative artistic work to scientific and technical laws and theories with the literary and artistic imagination without limitations in creating infinite worlds for an alien and miraculous creative structure based on mutilation and speculation within the limits of the absurd to try to transform it into a reasonable possibility and preach it in the distant future.

2. Highlighting an intellectual system in the scientific novel of artistic creative work that falls within the limits of suspicion in which there is no absolute truth, because everything that is real in science fiction is a hypothesis.

3. The abundance of cognitive and material inventions and innovations among the developed world countries for the purpose of competition, domination and hegemony fed by science fiction literature.

4. The weak presence of science fiction literature and its artistic marketing in the Iraqi reality in particular and the Arab world in general, and the inability to achieve a balance between the concepts of originality, modernity, progress and technology, as all efforts are made in Arab educational curricula to create a deep memory concerned with preservation without the skills of refining imagination, critical thinking, innovation and exploration.

\section{Research Objectives}

1. Knowing the literary and artistic conceptual frameworks of science fiction.

2. Revealing the implications of science fiction literature on the design of Star Wars movie posters.

\section{Research Limits}

1. Thematic boundaries: science fiction between the adventure of a virtual space opera and the alienation of future cities in the design of the movie poster (Star Wars) as a model.

2. Spatial boundaries: United States of America.

3. The temporal boundaries: 1977-2019.

\section{Defining Terminology}

1. Science fiction is fiction that deals with modern scientific discoveries and inventions in an imaginative way, and it is a branch of fictional literature in a fictional way human response to every progress in science and technology and the secrets of life on the other hand. The researcher adopts the previous definition completely, and its implications for the design of the movie poster (1).

2. Virtual Space Opera is a computer-generated virtual reality simulation technology that deals with audiovisuals, including space adventures. The term was invented in 1941 between the two world wars, which witnessed the revival of space opera stories by writers such as (Ian M. Banks) and (David Brin, and Dan Simmens) as Make adjustments to this literary subgenre through more sophisticated narrative forms, as two space opera stories are of particular importance. The first is a collection of related stories written by Philip Francis Nolan in 1928 and 1929, through which he introduced the character of Anthony Rogers, who was renamed Buck Rogers in Comic story series, and the second story that established this trend dates back to the same period and bears the title (Skylark) in 1928, written by E.Doc Smith. The procedural definition is that the Virtual Space Opera is a digital virtual world transcending the concerns of the recipient and his reality, combining 
science, politics, religion and economics within a multi-level materialistic and idealistic discourse of multicultural critical visions in its social and value dimension that work to undermine the fixed meaning and demolish the mental and logical systems towards producing a stimulating image of the imagination full of excitement and challenge. It considers the commercial market and considers power as a basis for change, victory, control, governance, and a guarantee of American supremacy (2).

3. Future Cities meaning utopia. It is a Latin word meaning (good place) or (impossible to exist) and the word has a pun and quarrelsome in meaning, meaning that a good place is found in nowhere, meaning that it does not exist at all. In another definition, it is a term that means a model for an ideal, imaginative society in which perfection is achieved or is close to it, and liberated from the evils that humanity suffers from, and there is no such society in a specific place on the Earth, but in imagined places and islands, and utopia remains a philosophical concept that seeks harmony of man With himself, with others and with society (3).

\section{THEORETICAL FRAMEWORK}

\section{Science Fiction}

It is a literary art based on imagination, and the fictional story is based on scientific discoveries, changes in the environment, space travel, and life on other planets. Philosophical, here the author imagines the results of these phenomena or theories, predicting the future, with its new moral, social, political and economic value dimensions, meaning that it depends on an imagined alternative to the reader's environment, and thus it is a means to promote scientific knowledge, and perhaps the most important characteristic of science fiction literature(4). It is the characteristic of adventure, exoticism, and political satire, in response to the human desire to seek to discover everything new, unknown and mysterious, through a funny fictional dress to make knowledge easier to handle and understand for the non-specialist recipient (5). Science fiction has played a great role in penetrating into the depths of the future and anticipating Its data, but some of it was able to succeed in achieving accurate ratios of the approach between imagination and reality. Science fiction literature is the outcome of the human imagination in light of what the possibilities offer For a scientific and its development potential, then the imagination is added to it, which is the revealing light of science, so imagination is a translation of science and it is a double-edged sword, science builds and also destroys (nuclear, biological and chemical weapons and technology may end human civilization, or raise it to the farthest corners of imagination, and with bankruptcy Ideologies, instability of states, failure of individualism, increased media pressure, revival of sectarian conflict, the development of digital knowledge and genetic engineering are all phenomena taking root in multiform images of future worlds.

\section{Future Cities in Science Fiction}

The cities of the future are closely related to the literary utopia with the scientific fiction, which is a verbal philosophical and literary structure, for an alternative historical structure that is canceled, that is, it derives its existence from the thought of a philosopher and a literary creativity (6). The good place or impossible to exist in the sense that the good place that exists in nowhere, meaning that it does not exist at all (7). The term (utopia) was used linguistically in 1516 through the title of Thomas More's book, which describes an island with a perfect order in a place There is no new world open to trade and colonial conquest, and utopian narratives have a mediating role between the familiar world of readers and the new world, with a tendency to elaborate on the struggle of the new society to achieve order and social justice, and the state in utopian novels (the utopia) is in a state of permanent war and works within a dangerous field (8). As the city suffers from two elements of crime and opposition from within, invasion and aggression from outside, which may exceed the limits established by the state, noting that the state needs permanent planning between accumulated growth and construction and development processes that do not affect if from the high rates of all kinds of pollution, diseases, illiteracy, class and social disparities (9).

\section{Star Wars, the Culture of the Era and its Transformations}

Cinema is the art of visual and audio accomplishments that take technology as a basic criterion for the level of meaning that reaches us. This standard depends on the craft and cognitive skills in the levels of dramatic narrative and the circumstances of the moving image (10). It has a digital presence as the contemporary culture that dominates the aesthetic discourse and is the basis of the postmodern cultural project based on breaking. The expected and the familiar as a hypothetical world transcending the concerns of the recipient and his reality, as they are multiple stylistic reflections of innovative techniques 
and amazing effects of virtual worlds that promote anxiety, nervousness, violence and high speed because of the great targeting of human life through images, ideas and deliberative concepts of fundamental problems within the aesthetic requirements of the controlled and effective formations in the person of the researcher. On the meaning of the event within subconscious imaginative structures based on the overlap of times, places, open ends, confusion, individual and collective labyrinths, with the ability to raise questions without answers to them within huge bold presentations in situations and the course of events in a way that increases the dramatic tension and increase the conflict to discuss the threads of the event and its details to create excitement and suspense marketing required (11).

\section{RESEARCH PROCEDURES}

\section{Research Community}

The research community is determined by the posters of the Star Wars series films from 1977 to 2019, and they number 9 films, and the number of posters for the series reached (100) various posters such as wall posters, video posters, electronic games, newspaper advertisements, magazines and websites. A poster after excluding what is similar, duplicate and unclear, what represents the original community of the research sample.

\section{Research Sample}

The researcher used the intentional (selective) sampling method as a percentage $(10 \%)$ of the total posters was chosen in cooperation with the Committee of Experts and it was chosen according to the multiplicity and diversity of its topics and the different titles and styles, and the number of posters reached. The selected (5) posters, according to the following justifications:

1. The ability of the selected posters to create the strange and miraculous world in the fictional structure based on prediction and speculation, within the limits of the absurd, to try to transform it into a reasonable possibility and preach it in the distant future, and turn it into an actual reality, such as robots, cyborgs, lasers, hidden surveillance cameras, spacecraft, and UFOs (12). And the latest cannons, planes and bombers.

2. The spread of electronic systems as huge storage units integrated into complex systems for exchanging information within a complex, comprehensive, comprehensive electronic environment that destabilizes the real and imaginary, mechanical and human poles, and as a structure of information within a group of systems that displays in a holographic form all the elements of the environment open without limits on the horizon in a global invocation of the concept Globalization is able to flatten and nibble all things and turn them into data ready for processing and manipulating minds, as in physical actions, as it becomes a property of the state and the subjugation of future cities to a huge entity managed by electronic systems takes the institutional form of a virtual reality that presents post-machine visions as a technological strategy to imagine the impossibility of separating the self from Electronic technology (13).

3. The popularity of these posters in the media and their influence in the field of advertising for a global market capable of the aesthetics of the image and the elements of visual formation to appeal to the taste of the recipient based on presenting bold offers to create meaning for portable images of a super-modern image that carries the magic of craftsmanship and the pleasure of knowledge that addresses the soul, the self, the body, existence and everything that is material and intangible.

4. All the selected posters agree with the idea (music) of light. The manipulation of the size, quantities, and values of light spots as a focus for highlighting, distinction, and affirming the principle of sovereignty in a harmonious environment is to evoke internal and poetic states of Star Wars heroes representing Western lifestyle and thought, which derive their expressive range from the contrasts of light and mysterious light values that are capable of on raising the motives and concerns of the soul to express the immateriality and the supreme sincerity to stimulate deep awareness in understanding the forms and contents of a complex cinematic system that has the ability to harmonize and embody an open time to explore the dimensions of the theory of evolution and its suitability for the idea of the survival of the preferred races of conflict as part of a historical narrative of natural selection to invest mental and physical talents for the project of future cities.

\section{Research Tools}

In order to reach the objectives of the current research, the researcher took the following steps:

1. Familiarize yourself with a group of local, regional and international posters, poster art styles and techniques. 
2. The researcher conducted various discussions with the graphic art professors and the cultural, knowledge and academic elites to increase the information and enrich the field of research.

3. The researcher intended to build a new research tool for this purpose, relying on the literature of the theoretical framework and classifying it into paragraphs that are grouped on major and minor axes, as in the following model.

\section{Validity of the Tool and Analysis}

The researcher presented the tool (observation form) to specialized experts to find out the extent of p. 2 for its purpose for analyzing the research samples. Experts agree that it is $(87 \%)$, and this percentage is ideal in measurement.

\section{the Stability of the Analysis Tool}

In order to extract the stability of the tool, the researcher followed the method of consistency between analysts. And the researcher (81\%), while the stability ratio between the first and second analysts is (83\%).

\section{Data Analysis}

Sample No. (1)

Poster Name: New Hope

Poster Date: 1977

Size: $100 \times 70 \mathrm{~cm}$

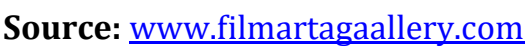

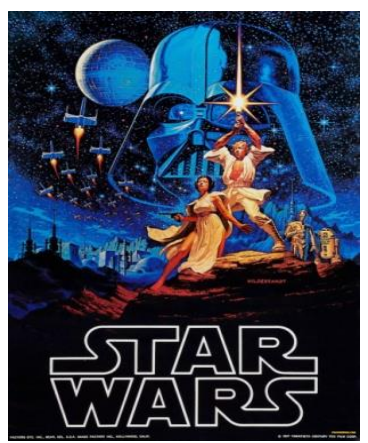

\section{General Description}

The poster contains typographical elements represented by the main title, which is the logo of his series of films (Star Wars) at the bottom of the poster and with a white hollow letter on a black background, while on the top is a drawn image containing a group of vocabulary distributed on the sides of the horizontal and vertical axis.

\section{Criticism and Analysis}

The idea of the poster is based on the conflict that breaks out in the galaxy after a group of politicians staged a coup that overthrew the legitimate authority in it, and the establishment of an evil empire that oppressed the inhabitants of the galaxy, so it was necessary to have a resistance movement led by Princess Leia (Carrie Fisher) seeking to restore freedom and democracy to the galaxy.

From what has been mentioned, we find that the poster responds to the film's drama based on the idea of adventure and the arms race, as it was in the fifties of the last century between the United States and the Soviet Union, as well as the contents of future wars as the climax of human adventure and the social, economic and environmental disasters they have of a nightmare devoid of all Humanitarian tendencies towards new forms of contemporary colonialism, as the horizon line in the poster design contains cities with architectural dimensions that adopt technology for huge buildings that have global land and air communication capabilities that achieve the crushing effect of a majestic technological scene for ultra-modern technical industrial societies in embodying the highest stages of organization, discipline and control It combines science and imagination in a manner that achieves victory due to the technical superiority of advanced mobile and fixed weapons with the superiority of the ideal hero in the character (Luke Skywalker) carrying a laser weapon within an elaborate dramatic plot by which the hero, the leader of the allied resistance, wins the attack on the highly developed space station called (Death Star) to face Commander of the Armies of Evil (Darth Vader) who wears an Iron Space Helmet as a cybernetic being a human-machine hybrid, It is more like an armored killing machine, far from any human, social or moral aspect. 
Sample No. (2)

Poster Name: Empire Restraining Blows

Poster Date: 1980

Size: $100 \times 70 \mathrm{~cm}$

Source: www.amazon.com

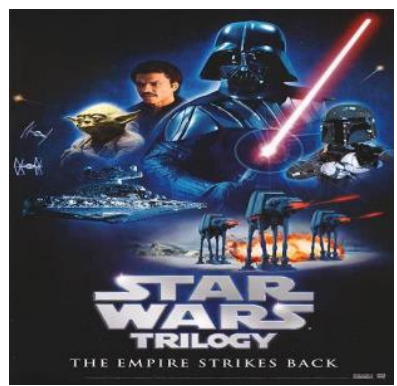

\section{General description}

The poster has function elements represented by the headline (Star Wars) and the title subtitle of Empire The strikes are tied at the bottom of the poster against a background of black value with a set of vocabulary words contrasting in size, shape, and light value representing the parties to the conflict as the tested empire continues under the leadership of the villain (Darth Vader) and the Emperor (Palpatine) chasing (Luke Skywalker) the hero of the film and the leader of the resistance group and one of the most important revolutionaries, as the Hungarian Empire succeeds by capturing one of Luke's friends when Luke was busy training and studying with teacher (Yoda) to learn the teachings of fighting the Jedi (an organization that keeps peace between the warring stars) Here the resistance led by Prince (Lea) establishes a base to fight the Hungarian Empire, but the tested empire was able to destroy the base.

\section{Criticism and Analysis}

Perhaps one of the characteristics of science fiction literature is the promotion of the idea of adventure in building capabilities and making the impossible possible from the logic of domination and appropriation for an approach that calls for the return of the invasion and occupation of technologically advanced beings that establish a pattern of tension in relations, as digital technology contributes to crystallizing their ideas and their own contents through the space surrounding people Their clothing, bodies, laser and animal combat tools, mythical shapes and fast-moving vehicles, both land and air, fit with the narratives of the epic space opera, as it deals with stories of a mythical nature with bright light reflections to confirm that the image does not convey a real reality, but rather a picture of an idea stimulating the imagination, reflections of light and flame and circular rings of spots of light data full of vitality, excitement and challenge commensurate with the goal of the poster, and is in harmony with a commercial market that employs advertising and propaganda, and the poster is not devoid of the characteristic of disassembly and fragmentation in the collection of an unrealistic combination of different times and places of humanity and a mechanism that confirms the time of automatic reproduction, division, repetition, multiplication of meaning and fragmentation, so the poster came with something from Complexity in the absence of order and the irrationality of scenes taking the causes of power the basis for change and victory.

Sample No. (3)

Poster Name: The Return of the Jedi

Poster Date: 1983

Size: $100 \times 70 \mathrm{~cm}$

Source: $w w w . i m p a w a r d s . c o m$

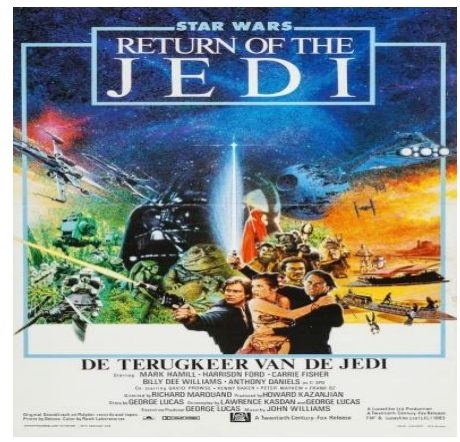

\section{General Description}

The poster has functional elements, lettering (title and text), figurative, color, and separating materials in the form of rectangular lines at the top and in the center, varying in size.

\section{Criticism and Analysis}

In this poster is an epic space opera with multiple responsibilities in the material and idealistic side, as null interpretations of aesthetic transformations that emphasize similarity, simulation, simulation and approaching reality with the use of modern bombing, intelligent and targeted weapons technology with wide destruction within field plans based on shock and awe, that we find in this The poster is a valuable cultural source that refuses to find a formula for a system of coexistence and peace as local and global 
values for a global adventure of hybrid beings and robotic societies seeking to achieve a landslide and final victory through the image of the fighter hero with laser weapons and around him the lethal weapons of the future; The hero, along with the revolutionaries, plans to attack and destroy the weapon (the Death Star) and kill the evil emperor (Palpatine) and end the suffering of the galaxy and restore freedom, democracy and the principles of rights to it as the hero (Luke Skywalker) tries to rescue his friend (Han Solo) from captivity, here the poster focuses on a mythical synthesis It has the center of sovereignty in the middle as an influential point of reference to attract the visual conviction of the audience with everything that is strange and urgent to daily life and control the power of visual seduction over the symbolic world to commodity values, visions and ideas for a global cultural project.

Sample No. (4)

Sticker Name: Attack Clones

Poster Date: 2002 AD

Size: $100 \times 70 \mathrm{~cm}$

Source: www.pinterest.com

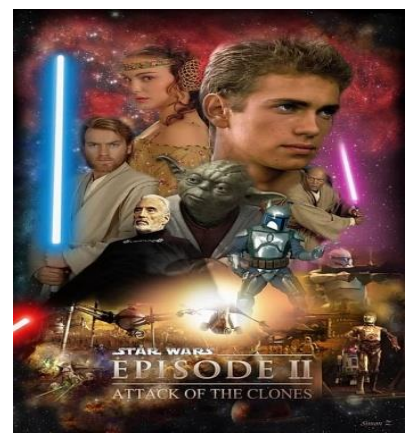

\section{General Description}

The poster has elements of a job represented by the main and secondary title at the bottom of the poster with linear breaks and a varying image density and varying in size, shape, value, color and texture, where a personal picture (Anakin Skywalker) is emphasized, the father of the young man (Luke) where his life is in danger, as it is assigned Locke protected one of the queens of the galaxy for fear of being assassinated due to the state of turmoil that the galaxy suffers from, which makes it close to the corner or near a civil war and the emergence of separatist movements calling for independence, which led to the emergence of challenges before the Jedi knights to maintain security and peace in the galaxy.

\section{Criticism and Analysis}

Perhaps the summit of the spirit of adventure and exploration that combines imagination and reality is cyberspace, a term coined by the American writer William Gibson in 1982, and the description of the virtual space for computer networks was used, in this poster we find the dramatic dimension of space opera from the real world, through Providing narratives of narratives of a military nature closely related to the US military in order to formulate a strategic defense initiative, and on the side of the cities of the future here, the city becomes a laboratory for electronic change with an out-of-control commercial spirit with a visual scene of a mixture of environmental pollution of the outer environment of the poster space and the dust of urban urban buildings and the vocabulary of the natural environment, As the city becomes the embodiment of a technological infrastructure for an automatic lifestyle that constitutes a sensory disturbance for the future constitutional cities, subject to remote control, which suggests the loss of human beings to their centralization and the slavery of replacement and automatic reproduction of the control of robots on the joints of the socio-economic city, and perhaps automatic self-control and automatic identity constitute a moral defeat for the absence Distinguishing between the differences between humans and the machine, and the mechanization of behavior within electronic units of control and domination, here We note the technological interference with the human body of the film heroes and its hybrid creatures as an electronic network for the global integration womb of the global era.

Sample No. (5)

Poster Name: Awakening Force

Poster Date: 2015 AD.

Size: $100 \times 70 \mathrm{~cm}$

Source: $\underline{w w w . p i n t e r e s t . c o m}$

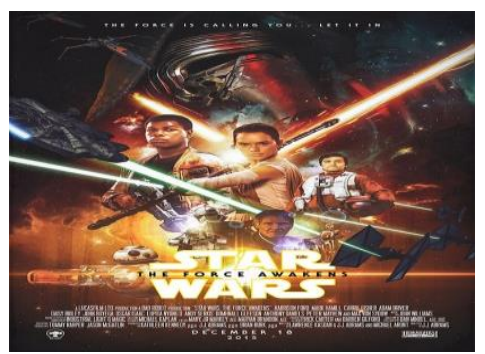




\section{General Description}

The poster has elements of a function that is the main title as a logo for the Star Wars series and a subtitle in the middle of the word (Stare Wars), the title of the film, with a small text in light value in a pyramidal style, the top of which is the main title and the top of the pyramid, a radiant glowing light image for vocabulary adventure The new space, as with the destruction of the weapon (the Death Star), the Jedi fighters disappear, including (Luke Skywalker), and here new evil powers emerge from the rubble of the evil empire seeking to control the galaxy, showing signs of resistance against the new evil forces, while General (Leah) finds her brother (Luke) to help her overcome the forces of evil.

\section{Criticism and Analysis}

In this visual space we find the literature of the globalization era represented by the adventure of exploration and reconnaissance represented by the complex merging of technology through cyberspace, for an open environment that brings together calculated elements of a deadly electronic and radiological system, as an activity of a global system of modern capitalism for a future era, representing an accurate description of modern culture in which electronic systems Which dominates the world to put forward the post-machine within the strategies of imagination that it is impossible to separate between the self, technology and human identity based on formulating the idea of singularity as an evolutionary model of a superhuman era with human and mechanical intelligence, bearing a spiritual character in this poster to reflect a promise of advancement as false facts classified by the media and companies And governments and groups are caught between a horrific present that is free from moral judgment and social criticism fed by violence that invades the screen as a cancerous growth drowning in exaggeration, here the explosion becomes the core of the subject of storytelling that confuses the meaning and complicates the narration. Made to create shock and awe encapsulated in a charming fairytale aesthetic Super heroes of a human being with robotic organs that are unleashed by the practice of violence to burn, kill, tear, and prey to narrate the bloody facts of a political and social reality steeped in violence.

\section{RESULTS}

1. Science fiction literature came through Star Wars posters in a manner characterized by an inward orientation, that is, within the human psyche not only to spread terror and fear, but to criticize the human way of life as it stands on the brink of the abyss, the city and the technical and technological devices and machines contributed to the (objection) of the human being became submissive her eagerness behind a desperate wish, within the ultra-modern capitalist consumer aesthetics of hybrid planetary cinema with an interpretive culture in order to liberate trade exchange, narrative, violence, lust and tastes.

2. Science fiction literature came through Star Wars posters, employing the idea of travel, conquest and conflict with other galaxies, whose mission is to spread the western lifestyle among the inhabitants of other planets, as they are paranormal heroes who fight unscrupulous, honorable, and compassionate aliens who seek to destroy the earth.

3. Science fiction literature came through Star Wars posters with its ability to critique the phenomena of society in its political, social and economic aspect, and the nature of natural relations through the ability of technical inventions to influence and change the forms and patterns of human behavior, and to imagine the fate of future cities. Biology and environment sciences are tools that the power exploits as means of social control

4. . Science fiction literature came through Star Wars posters with an eccentric adventure through the propensity of man to the agents of destruction and not peace with disgusting, ugly insect and animal creatures lending humans intelligence and skill as a missing link from the missing links of evolution, as they are subject to human greed and selfishness.

5. Science fiction literature came in Star Wars posters with structures, natures, and a perception that takes a hostile stance on the different other as evil and fierce aliens with a strange shape that necessitates entering with them in a war of world for control and domination.

\section{CONCLUSIONS}

1. The ability of American cinema through Star Wars posters to present a person as an estranged being with value and his thinking goes towards the factors of self-destruction and tearing his being when he is limited to killing as a means of entertainment and entertainment, which deepens the civilizational predicament for the future man, as material and technical civilization robs him of his spirit and reassurance when he becomes a slave to God Which provides him with means of 
livelihood and survival in exchange for the deprivation of his freedom and his humanity, for man is the enemy of himself and the guarantor of its destruction, for the narrative plots of Star Wars are nothing but critical, moral, social and psychological reviews within a biological genetic engineering and cybernica to transform the individual, social and national memory into a commodity in a form of virtual tourism.

2. The ability of American cinema, through Star Wars posters, to consider inevitable wars as inevitable and the necessity to draw a hostile relationship with the other on the ground or outside it between individuals and groups of color or between the sexes. There is no peace or friendship with the war of the worlds and transgressing physical boundaries towards demolishing the expression of gender. Social, identity and a weak perception of history because our bodies and our consciousness in itself have become affected by technology. Here alienation has transformed into a state of being.

3. The ability of American cinema through Star Wars posters to highlight the pessimistic view that is summarized by the attack and mutual defense between the good and the bad as a military view of the overwhelming hegemony of colonial capitalist tendencies that do not find in socialist and communist ideas a place for friendship or peace in the case of domination and surrender.

4. The ability of American cinema through Star Wars posters to present literary propositions for a scientific fiction capable of posing questions that dominate most of the Western narrative, including why we seek to colonize and conquer planets? From the presence of the Western self and its narcissism, here cinema began to tend toward philosophy with the claim of wisdom in the purpose of traveling to the planets as a type of American foreign invasion films and fear of sabotaging military installations where the national dimension is manifested and it is a coded expression of the demonization of communism for the purposes of military escalation during the Cold War.

5. The ability of American cinema, through Star Wars posters, to confirm the apparent and essential side of the reality of science fiction. The apparent motivation is adventure, exploration and cognitive theory, while the essential motive is conquest, domination and occupation.

6. The ability of American cinema through Star Wars posters to build spaceships with exciting and amazing technological designs, to emphasize the concepts of the ability to manage conflict, maneuver and survive in difficult circumstances to confirm the concept of freedom, salvation, emancipation, and saving the human race, whatever the external influences (winds, rain, storms, etc.) Fires through central technological control of a successful adventure that achieves victories as the culmination of human adventure.

\section{RECOMMENDATIONS}

1. Rejection of the false American political, cultural and economic approaches in promoting and spreading freedom, democracy and the principles of rights as a pretext to achieve chaos, control and destruction.

2. Rejection of the American virtual space approaches in the technical and technological side by borrowing concepts of alienation, the unfamiliar and the absurd as symbolic quotations of the forces of chaos and destruction represented by composite beings of hybrid creatures that do not have a fixed identity or history, which are approaches that converge with Washington's approaches by adopting the superior and overwhelming power and employing a strong liberal economy and a mighty digital media power Capable of dismantling the self and the cosmic system.

3. Crystallization of cultural and technical knowledge coordination for the digital competition of cultural production institutions to enter the stage of a civilized race that strengthens the local and national cultural identity and responds to market standards and the cultural consumer product.

4. Establishing a cultural project for a national identity that touches on the reality of imagination and innovation for a symbolic, interactive framework of multiple visions and ideas that takes on legend and heritage renewable sources of meaning for a global digital art work.

\section{REFERENCES}

Brantzos, Nicolas, Travels to the Future, T.: Ali Naguib Ibrahim, Academia International, Beirut, 2009.

Brucker, M. Keith, Thomas, Anne Marie, The Reference in Science Fiction Novels, 1st Edition, National Center for Translation, Cairo, 2010.

Bernery, Maria Luisa, The utopia throughout history, T.: Attiyat Abu Al-Saud, The World of Knowledge Series, Issue (225) for the year 1997, Kuwait.

Al-Baalbaki, Mounir, The Dictionary of Flags Al-Mawred, 1st Edition, Dar Al-Alam Al-Malayn, Beirut, 2016, p.82. 
Al-Talawi, Muhammad Naguib, Science Fiction Stories in Arabic Literature, Dar Al-Mutanabi, Beirut.

Al-Jisway, Khalil, the Arabic novel and cinema, the problem of literature and identity in Arab cinema, AlRafid, Issue 188, April, 2013 AD.

Al-Zawawi, Mahmoud, Masterpieces of Cinema, The 100 Best American Films, 1st Edition, Al-Ahlia Publishing and Distribution, Amman - Jordan, 2006 AD.

Sibed, David, Introduction to Science Fiction, 1st ed., T: Nevin Abdel Raouf, Egypt - Cairo, 2016 AD.

Al-Sahn, Salih, Film and television taste, Al-Fath for printing and reproduction, Baghdad, 2018.

Magdy Wahba and Kamel Al-Muhandis, Dictionary of Arabic Terms in Language and Literature, Lebanon Library - Beirut, 1979.

Mahmoud Masoud, with the shawamakh in their towers, Dar Al-Hilal, Cairo, 1981.

Al-Yaseen, Muhammad Abdullah, Science Fiction in Modern Arabic Literature in Light of Comparative Studies, Unpublished Master Thesis, Al-Baath University, College of Arts and Human Sciences, Damascus, 2008.

Yebovetsky, Gil and Sirojan, Screens of the World in the Era of Super Modernity, 1st Edition, T: Rawya Sadiq, National Center for Translation, Cairo, 2012.

D. S. Q. Al-Yasiri and A. J. Obaid, "A New Approach for Object Detection, Recognition and Retrieving in Painting Images," Journal of Advance Research in Dynamic and Control System, vol. 10, no. 2, pp. 2345-2359, 2018.

Science Fiction, Scientific and Cultural Journal, Ministry of Culture, Syria, Damascus, Fifth and Sixth Issues, December and January, 2008-2009.

Ali Hussain Fawaz, Digital Cinema With Light Cameras, Tawasul Magazine, Media and Communications Commission, Baghdad, 2007, Issue 19.

The global information network www.alhurra.co.

The global information network www.ar.wikipedia.org.

Global Information Network: www.ar.wikipedia.org. 